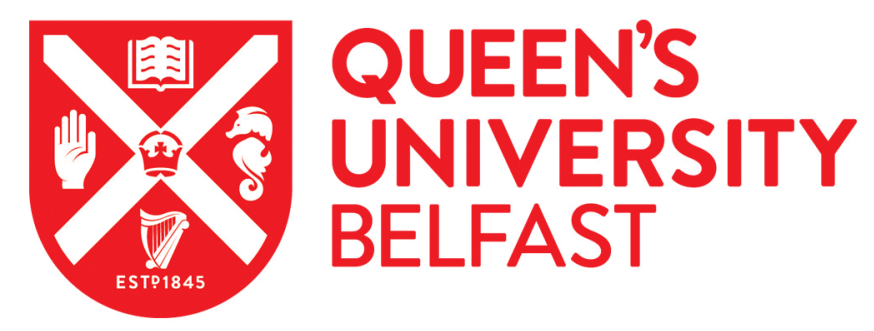

\title{
Out-of-Phase Synchronization of a Small Alternator
}

Best, R. J., Morrow, D. J., \& Crossley, P. A. (2007). Out-of-Phase Synchronization of a Small Alternator. In 2007 IEEE Power Engineering Society General Meeting: Proceedings (IEEE Power Engineering Society General Meeting). Institute of Electrical and Electronics Engineers Inc.. https://doi.org/10.1109/PES.2007.385619

\section{Published in:}

2007 IEEE Power Engineering Society General Meeting: Proceedings

\section{Document Version:}

Peer reviewed version

Queen's University Belfast - Research Portal:

Link to publication record in Queen's University Belfast Research Portal

\section{Publisher rights}

Copyright 2007, IEEE.

This work is made available online in accordance with the publisher's policies. Please refer to any applicable terms of use of the publisher.

\section{General rights}

Copyright for the publications made accessible via the Queen's University Belfast Research Portal is retained by the author(s) and / or other copyright owners and it is a condition of accessing these publications that users recognise and abide by the legal requirements associated with these rights.

Take down policy

The Research Portal is Queen's institutional repository that provides access to Queen's research output. Every effort has been made to ensure that content in the Research Portal does not infringe any person's rights, or applicable UK laws. If you discover content in the Research Portal that you believe breaches copyright or violates any law, please contact openaccess@qub.ac.uk. 


\title{
Out-of-Phase Synchronization of a Small Alternator
}

\author{
R. J. Best, D. J. Morrow, Member, IEEE, and P. A. Crossley, Member, IEEE
}

\begin{abstract}
In modern power systems with large amounts of dispersed generation the islanding of distribution networks is now a realistic possibility. Islanding can be implemented following system disturbances to improve the continuity of electricity supply and prevent blackout. Before this can become widespread many issues must be considered. One of the major concerns and the topic of this paper is out-of-phase synchronization and its effect on the system. To investigate this, a series of tests were preformed on a small $31.5 \mathrm{kVA}$ alternator. The results show the differences in peak torque and current between synchronizations where the rotor either leads or lags the main system. They also let the authors propose a maximum acceptable synchronization angle for small generators that is higher than that used for larger plant. A simulation has been performed to give the expected system voltage deviations when re-connecting an island out-ofsynchronously to the main system.
\end{abstract}

Index Terms--Alternators, Dispersed Generation, Islanding, Synchronization, Synchronous Generator Transient Analysis

\section{INTRODUCTION}

$\mathrm{I}^{\mathrm{s}}$ SLANDING of power networks following system events is receiving much attention as a way to improve continuity of electricity supply. One of the main technical concerns is the possibility of out-of-phase synchronization of the island to the main system. This is because large shaft torques and winding currents can occur during out-of-phase synchronization, causing stress to the generator and in the worst case damaging it. Severe system voltage dips are also a characteristic. To prevent this from happening most islanding schemes require a pre-definition of where the island will form. A synch-check relay is then placed at the island boundary or point of common coupling (PCC).

To allow for a more flexible situation where the physical size of the island has no set limits and to avoid having to place

This work was supported by Kelman Ltd and the Department for Employment and Learning (DEL) under the Co-operative Award in Science and Technology (CAST) scheme.

R. J. Best is with the Power and Energy Research Centre, Queen's University Belfast, Belfast, Northern Ireland, BT9 5AH (phone: 0044 (0) 28 9097 4341; fax: 0044 (0) 289066 7023; e-mail: rbest02@qub.ac.uk).

D. J. Morrow is with the Power and Energy Research Centre, Queen's University Belfast, Belfast, Northern Ireland, BT9 5AH (e-mail: dj.morrow@ee.qub.ac.uk).

P. A. Crossley is with the Electrical Energy and Power Systems Group, The University of Manchester, Manchester, UK, M60 1QD (e-mail: p.crossley@manchester.ac.uk). synch-check relays at each PCC, synchronous islanded operation has been suggested, [1], [2]. Synchronous islanded operation is a method of islanding where the islanded system is kept in synchronous with the main system while not being electrically connected. This is achieved by transmitting a reference signal from a secure part of the network and using global positioning satellite (GPS) synchronized time stamping to make sure that the island and mains voltage waveforms can be aligned with minimum phase difference error.

Avoiding out-of-phase synchronization relies upon the quality of the control scheme. It has been shown in [2] that the phase difference error can be removed, remaining stable in steady state and recovering after load disturbances. Other work by the authors for future publication has been conducted on a diesel generator. Inevitably any load disturbances in the island will cause a temporary phase difference between the two systems. This error may be increased by voltage phase shift through the system.

It is therefore useful to know how synchronization angle will affect the system and be able to determine a value for the maximum acceptable re-close angle. This paper is concerned with observing the effect of synchronizing a small alternator out-of-phase with the main system. Attention is paid to peak torque, current and voltage deviation.

\section{OUT-OF-PHASE SYNCHRONIZATION OF A SMALL ALTERNATOR}

The transient response of small alternators used in dispersed generation differs from that of larger generators discussed in [3], [4], in that due to short shaft lengths and because the alternator contains much of the inertial mass, resonance of torsional forces is highly unlikely. This means that on small generators synchronizing out-of-phase should be possible at larger angles without causing damage.

In order investigate how an islanded system will be affected by out-of-phase synchronization to the main system a number of tests were carried out on a $31.5 \mathrm{kVA}, 415 \mathrm{~V}$, 4-pole alternator with parameters as given in Table I. The set-up uses an ac drive controlled induction machine as a prime mover coupled to the alternator, Fig. 1. Rotary encoder feedbacks from the induction machine and a mains connected synchronous motor are used to keep the alternator in phase with the main system. 


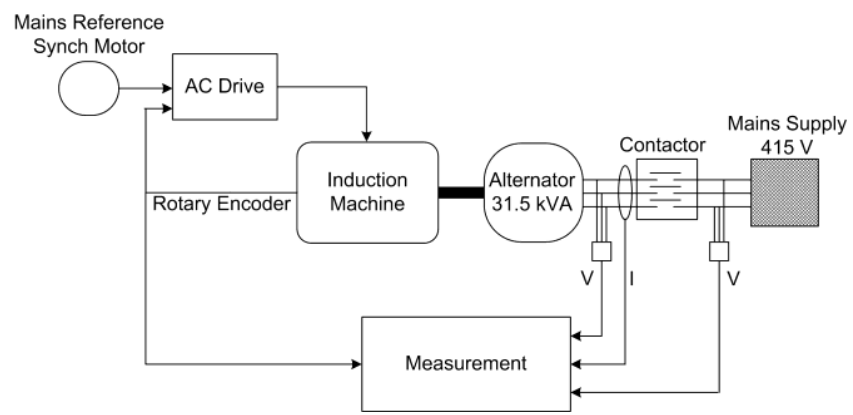

Fig. 1. Experiment Set-up

An offset can then be used to set the phase difference at any desired value for the test. Phase current and voltage measurements are taken from the alternator terminals with frequency and rotor angle being measured using the rotary encoder attached to the induction machine. From these measurements, the electrical and mechanical transients during synchronization can be observed.

The plots in Fig. 2 and Fig. 3 show three-phase voltage and current waveforms during synchronization where the rotor lags the mains by 50 degrees at the time of re-closure. In the plots this occurs at zero seconds. Fig. 4 and Fig. 5 are for the same

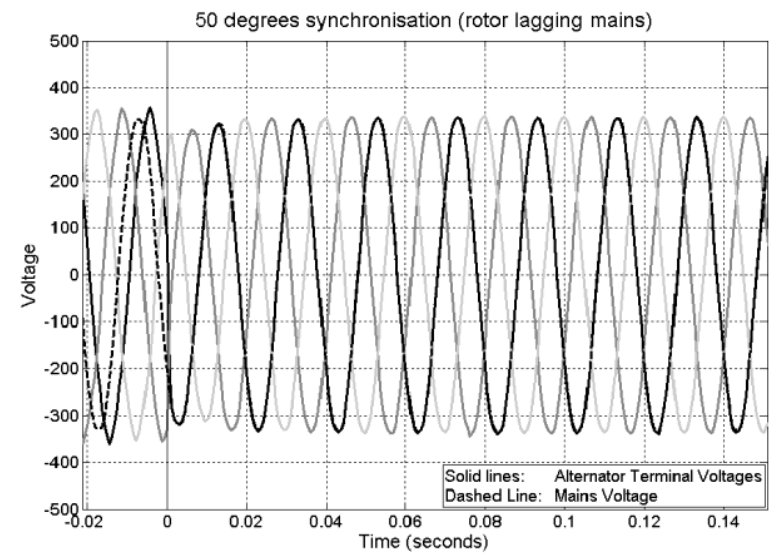

Fig. 2. Plot to show three phase voltage waveforms during out-of-phase synchronization of 50 degrees where the rotor lags the mains

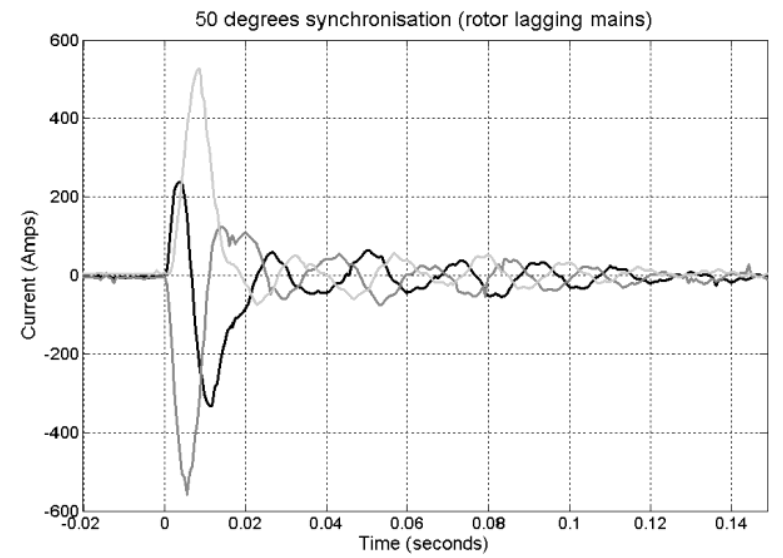

Fig. 3. Plot to show three phase current waveforms during out-of-phase synchronization of 50 degrees where the rotor lags the mains magnitude of angle but where the rotor leads the mains at the time of re-closure. It can be seen that the synchronization of the voltage waveforms is immediately followed by a high but short lived current.

TABLE I

PARAMETERS FOR 31.5 kVA ALTERNATOR

\begin{tabular}{llc}
\hline \hline \multicolumn{1}{c}{ Symbol } & \multicolumn{1}{c}{ Paramter } & Value \\
\hline $\mathrm{X}_{\mathrm{d}}$ & d-axis reactance & $2.2 \mathrm{p} . \mathrm{u}$. \\
$\mathrm{X}_{\mathrm{q}}$ & q-axis reactance & $1.1 \mathrm{p} . \mathrm{u}$. \\
$\mathrm{X}_{d^{\prime}}$ & d-axis transient reactance & $0.12 \mathrm{p} . \mathrm{u}$. \\
$\mathrm{T}_{\mathrm{d}}{ }^{\prime}$ & d-axis transient time constant & $30 \mathrm{~ms}$ \\
$\mathrm{X}_{\mathrm{d}}{ }^{\prime \prime}$ & d-axis sub-transient reactance & $0.059 \mathrm{p} . \mathrm{u}$. \\
$\mathrm{X}_{\mathrm{q}}{ }^{\prime \prime}$ & q-axis sub-transient reactance & $0.084 \mathrm{p} . \mathrm{u}$. \\
$\mathrm{T}_{\mathrm{d}}{ }^{\prime}$ & d-axis sub-transient time constant & $3 \mathrm{~ms}$ \\
$\mathrm{~T}_{\mathrm{a}}$ & aramature time conatant & $4 \mathrm{~ms}$ \\
$\mathrm{~J}_{1}$ & induction machine inertia & $0.45 \mathrm{kgm}^{2}$ \\
$\mathrm{~J}_{2}$ & alternator inertia & $0.17 \mathrm{kgm}^{2}$ \\
\hline \hline
\end{tabular}

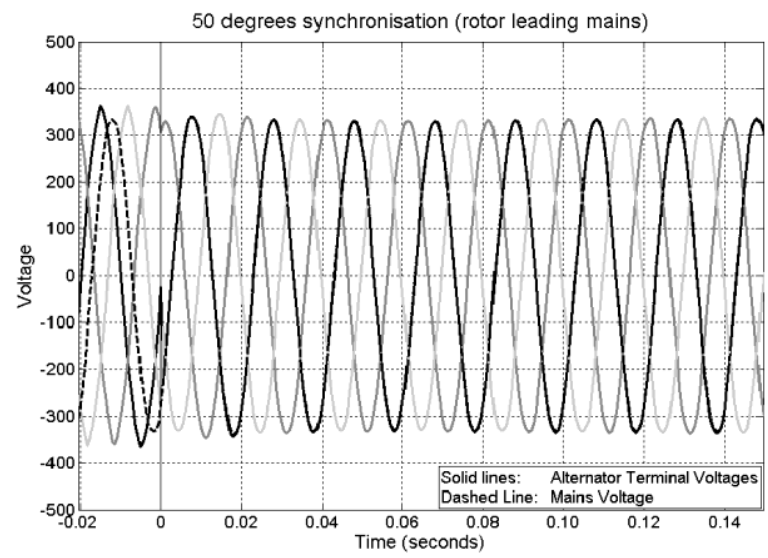

Fig. 4. Plot to show three phase voltage waveforms during out-of-phase synchronization of 50 degrees where the rotor leads the mains

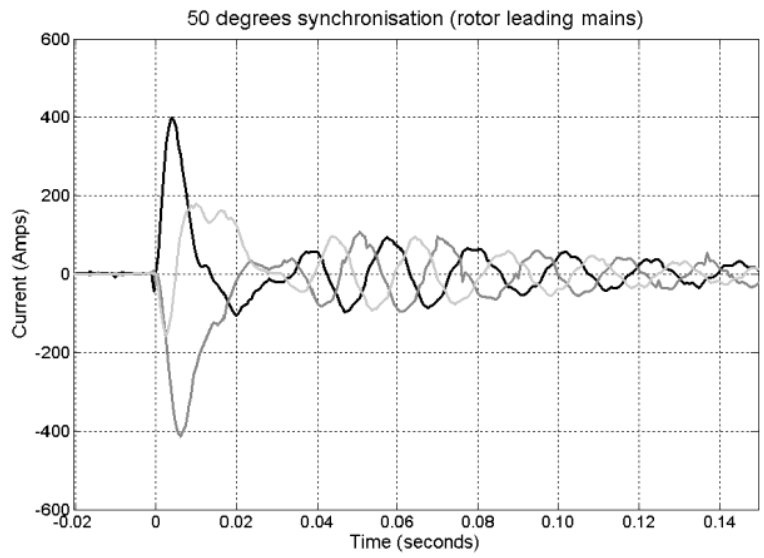

Fig. 5. Plot to show three phase current waveforms during out-of-phase synchronization of 50 degrees where the rotor leads the mains 


\section{A. Peak Current}

The physical process that occurs during an out-of-phase synchronization is complicated. It is similar to the more familiar three-phase short circuit. Both of these events are characterized by a sudden change in terminal voltage, however from the theorem of constant flux, the flux linking a circuit cannot change immediately.

As the rotor moves away from the position where it was at the time of the event, the mutual flux linking the rotor and stator circuits is not maintained at a constant value. In order for the flux linking each individual circuit to remain unchanged, a dc current must flow in each circuit to create a leakage flux. The effect of rotation on the constant flux linking each circuit is to induce fundamental frequency currents in circuits on the other side of the air-gap. The fundamental frequency current flowing in the rotor circuits, induced by the constant stator flux, results in a double fundamental frequency current component in the stator.

The fundamental frequency currents on one side of the airgap produce magnetomotive force (MMF) in opposition to the MMF required for constant flux linkage on the other. Thus to keep the constant flux linkage balance, more dc current must flow in the circuits. This is observed as a reduction in the reactance as viewed from the stator, referred to as the subtransient reactance. When the rotor has moved through half a cycle, the resultant leakage flux needed to maintain constant flux linking the rotor and stator circuits is at its maximum. In a $50 \mathrm{~Hz}$ system this is 0.01 seconds after the event. Due to saliency the peak current does not necessarily occur when the rotor has moved half a cycle from the event. For a rotor lagging mains synchronization the peak current happens before $0.01 \mathrm{~s}$ and for a rotor leading mains synchronization it occurs after $0.01 \mathrm{~s}$.

The currents cause energy to dissipate through resistance in the various circuits. Since there is no source of energy to keep the flux linkages at a constant value, they decay. In the stator, the dc current decays at a rate determined by the stator resistance and reactance, known as the armature time constant. Fundamental frequency rotor currents and double frequency stator currents decay at the same rate as the stator dc current. In the rotor energy dissipates in the field winding and damper circuits. The rotor flux can be split into two components, each decaying with a different time constant. The dc currents in the damper circuits decay faster than those in the field winding. As the resultant rotor flux decays, so do the fundamental frequency stator currents.

In a small alternator such as the one referred to here, the time constants are short. The flux decays significantly by the expected time of the peak current. The actual peak current occurs before the time suggested by the theorem of constant flux linkage. Furthermore the peak current from a rotor leading mains synchronization is smaller than during a rotor lagging mains synchronization at the same angle. This can be explored mathematically using the equations for current given in [5] for synchronizing an alternator against an infinite bus. From the experimental results in Fig. 6 which shows the resultant positive sequence current variation with time and Table II, notice that the peak current is higher when the rotor lags the mains at synchronization.

The plot in Fig. 6 compares the results of a no-load three phase short circuit with synchronizations of 50 degrees. It can be seen that the short circuit has a higher peak current value than both of the out-of-phase synchronizations. An alternator is designed knowing that a three-phase short circuit may happen on occasion. It is mentioned in [6] that a well designed alternator should not be damaged by faults where the peak currents do not exceed about $85 \%$ of the no-load short circuit value. The peak current of the 50 degrees synchronization with rotor lagging mains is around but not exceeding this limit.

Also notice that he currents decay to zero after synchronization, while the short circuit current has a steady state value because the alternator is separately excited. If the exciter were fed from the alternator through an automatic voltage regulator, AVR, the short circuit current will also decay to zero as the supply voltage to the AVR is removed when the alternator terminal voltage drops to zero straight after the event.

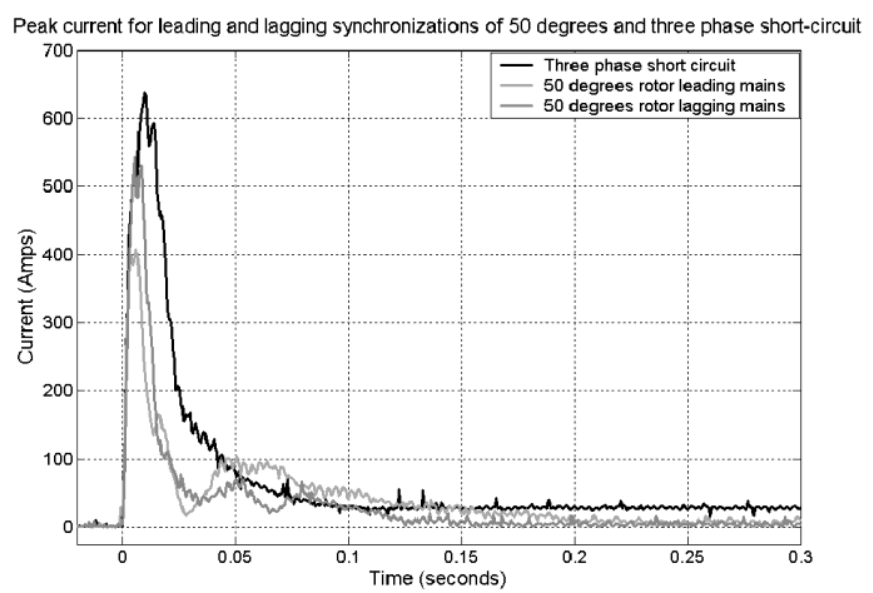

Fig. 6. Plot to show resultant positive sequence current for out-of-phase synchronizations of 50 degrees leading and lagging, and a 3-phase shortcircuit under no-load

TABLE II

PEAK CURRENT AND ELECTRIC POWER DURING TESTS

\begin{tabular}{lcr}
\hline \hline \multicolumn{1}{c}{ Test } & Current & Electric Power \\
\hline 3-Phase Short Circuit & 15.0 p.u. & \\
Rotor Leads Mains, 50 degrees & 10.0 p.u. & 5.2 p.u. \\
Rotor Lags Mains, 50 degrees & 12.7 p.u. & 10.0 p.u. \\
\hline \hline
\end{tabular}

\section{B. Peak Power and Torque}

The instantaneous electrical power is calculated from the phase voltages and currents, Fig. 7. As with peak current the magnitude of peak electrical power is larger when the rotor is lagging the mains at synchronization. Table II shows the peak electric power measured by the tests. When the power flows into the alternator during a rotor lagging mains 
synchronization, all the power involved is measured, with the exception of magnetizing power supplied by the exciter and steady state losses due to friction and windage supplied by the prime mover. This means that the measured power magnitude is equal to the synchronizing power that is acting to reduce the angle between the rotor and stator, plus any ohmic power loss due to resistance in the windings. When electric power flow is out of the alternator during a rotor leading mains synchronization, the measurement equals the synchronizing power minus the ohmic power loss, thus it tends to be smaller.

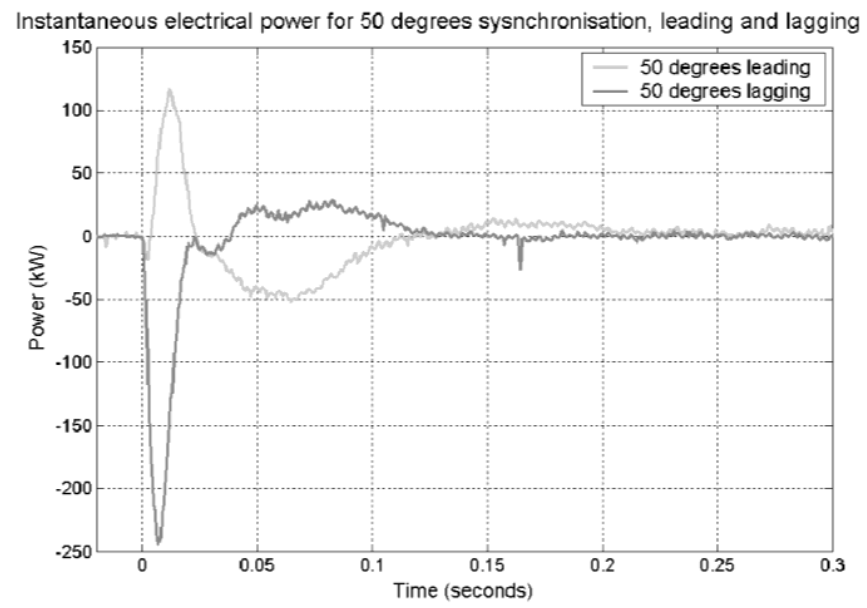

Fig. 7. Plot to show transient electrical power for out-of-phase synchronizations of 50 degrees leading and lagging

Rotary encoder pulses provide information on the frequency and rotor angle transients, and can also be used to calculate the air-gap torque. Fig. 8 shows the frequency transients after synchronizations at 50 degrees with the rotor leading and lagging the mains, and also for a three-phase short circuit with the alternator unloaded. The variation of load angle during the 50 degrees synchronization events are in Fig. 9. The rotor leading mains graphs have a higher frequency deviation and rotor angle overshoot.

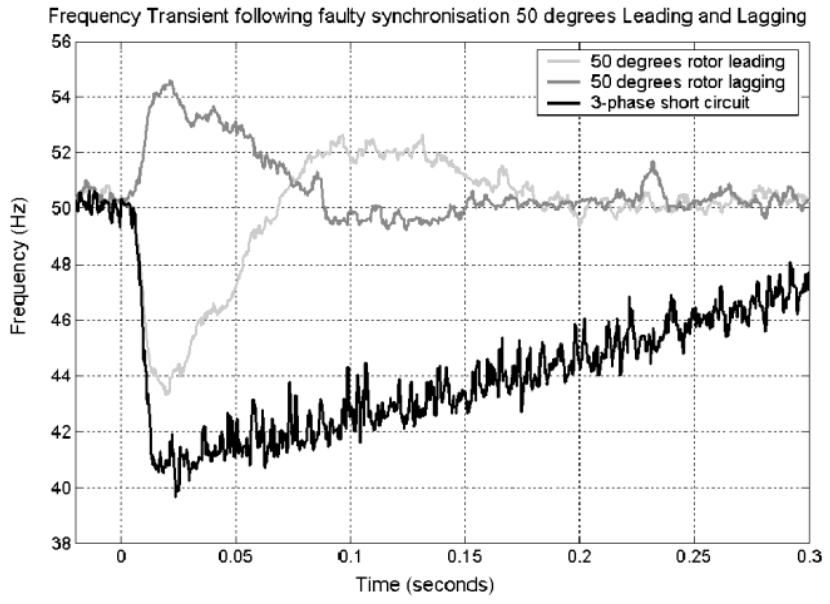

Fig. 8. Plot to show frequency variation during out-of-phase synchronizations of 50 degrees leading and lagging
The air-gap torque is calculated by the equation in (1). Since the total plant inertia, $J$ is known by adding $J_{I}$ and $J_{2}$ from Table I, the maximum rate of change of frequency can be used to calculate the peak air-gap and shaft torques during the disturbance. $\Delta T$ and $\Delta P$ are the torque and power imbalances and $\omega_{m}$ is the mechanical speed of the alternator.

$$
\Delta T=\frac{\Delta P}{\omega_{m}}=\frac{\text { poles }}{2} J \frac{d^{2} \delta}{d t^{2}}
$$

The peak air-gap torques are shown in Table III. From the air-gap torque attention is directed towards two points. Firstly, that the three-phase short circuit torque is higher than that of both the 50 degrees synchronizations. Secondly, that the magnitude of the peak torque is higher when the rotor leads the mains prior to synchronization than when the rotor lags the mains. This is the opposite situation to that posed in Fig. 7 concerning the electrical power.

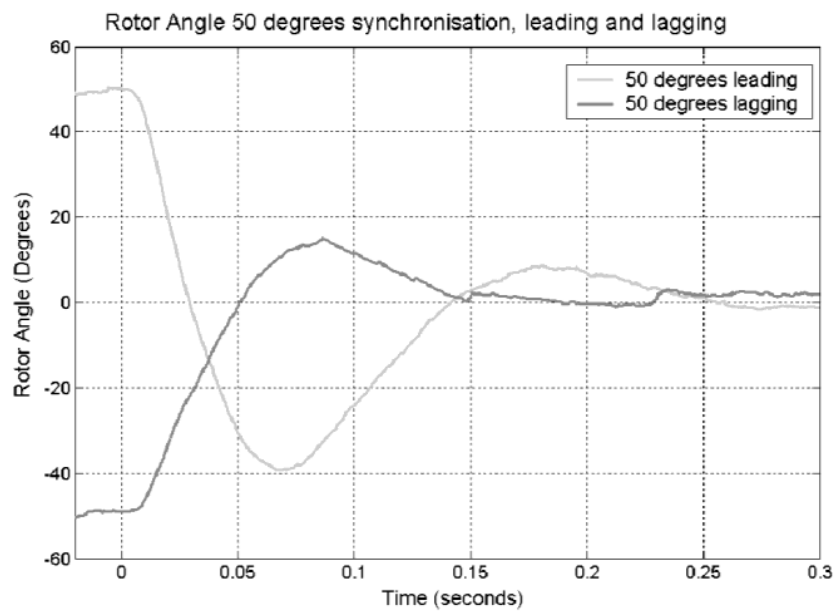

Fig. 9. Plot to show rotor angle variation during out-of-phase synchronizations of 50 degrees leading and lagging

TABLE III

PEAK AIR-GAP TORQUE DURING TESTS

\begin{tabular}{lr}
\hline \hline \multicolumn{1}{c}{ Test } & Peak Torque \\
\hline 3-Phase Short Circuit & 13.8 p.u. \\
Rotor Leads Mains, 50 degrees & 9.6 p.u. \\
Rotor Lags Mains, 50 degrees & 7.4 p.u. \\
\hline \hline
\end{tabular}

The air-gap torque comes from any power derived by flux linking across the air-gap, and includes both a synchronization torque acting to reduce the angle between the rotor and stator axis and a unidirectional torque component from ohmic losses, [5], [7], [8]. Not all the ohmic power loss contributes to a unidirectional torque. The losses that do not provide torque come from dc components of current that decay quickly in the various stator and rotor circuits, as well as the magnetizing power loss in the rotor supplied by the exciter. As the alternating components of current are due to flux crossing the air-gap, then any ohmic loss that is a consequence of this will also be observed as a unidirectional torque. This unidirectional torque always acts against the direction of rotation and so will 
slow the rotor. Thus for air-gap torque, if synchronization happens when the rotor is leading the mains, the unidirectional torque adds to the synchronizing torque that acts to reduce the rotor angle by decelerating the machine. If synchronization occurs when the rotor is lagging the mains, the synchronizing torque acts to accelerate the machine and against the unidirectional torque, meaning the resultant torque is smaller.

This is not the only factor contributing to the difference in peak torque. In a rotor leading mains synchronization the peak torque occurs at a frequency below $50 \mathrm{~Hz}$, while in a rotor lagging mains synchronization it happens at a frequency above $50 \mathrm{~Hz}$, Fig. 8. This means that even if unidirectional torque is neglected and the mechanical powers involved are assumed equal, a higher torque in a rotor leading mains synchronization is expected.

\section{Estimation of Peak Power and Torque}

To give an appreciation of the effects of larger phase angles the plot in Fig. 10 gives an estimation of the peak torque and electric power for different synchronization angles in keeping with the theory [5], [7]. A positive angle represents the rotor leading the mains. The largest values of peak power and torque occur at around $120^{\circ}$ due to $X_{d}$ "' being smaller than $X_{q}$ "'.

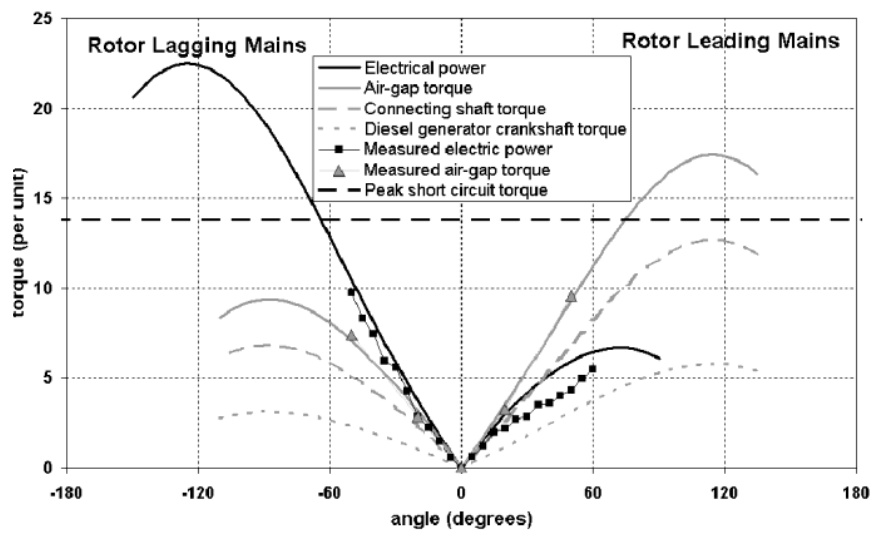

Fig. 10. Plot to show peak torque variation with load angle

To this point only the air-gap torque, $T_{a g}$, has been calculated. However since the alternator is a robust piece of equipment, any mechanical damage is more likely in the shaft coupling, or engine crankshaft if the prime mover were a diesel engine. As the system has high electrical damping and there is a short shaft length it allows mechanical damping and shaft spring constants to be ignored. A simplified equation (2) can be used to give the proportion of the torque experienced by the shaft connecting the alternator to the induction machine, $T_{\text {shaft. }}$.

$$
T_{\text {shaft }}=T_{a g} \frac{J_{1}}{J_{1}+J_{2}}
$$

The ratio of inertias means that the connecting shaft torque is about $73 \%$ of the air-gap torque.

In a diesel generator the alternator usually contains most of the inertia, thus the crankshaft torque is likely to be no more than $1 / 3$ of the air-gap torque. The induction machine connecting shaft torque and expected diesel generator crankshaft torque are plotted in Fig. 10.

If it is taken that generation units may experience a threephase short circuit and so are designed to cope with such, as long as the peak torque and current generated by an out-ofphase synchronization is less than this, the machine should not be damaged. Under this supposition a 50 degrees synchronization of a unit with short shaft length, either with the rotor leading or lagging the mains is acceptable. Note that if the alternator is connected when the rotor leads the mains there is a higher torque and if connection is when the rotor lags the mains there is a higher current.

\section{Simulation of Voltage Transients During Re- CONNECTION OF AN ISLANDED SYSTEM}

While high shaft torques and winding currents are of concern when considering the generation unit, it is the voltage transients that will have most affect on the system loads. The effects of voltage disturbances are detailed in [9].

With experimental tests performed on the $31.5 \mathrm{kVA}$ alternator, small but observable voltage transients are measured, see Fig. 2 and Fig. 4. For the rotor lagging the mains, there is a voltage dip due to high inrush current. When the rotor leads the mains there is a voltage rise due to the high output current.

As an islanded system will likely include many parallel connected generators, the effect of voltage deviations will be much higher than seen in the experiment using a single 31.5 $\mathrm{kVA}$ alternator. To investigate this further a simulation was performed on a model distribution network modified from that in [10], using DIgSILENT. The system model represents a residential network with a load demand of $1.89 \mathrm{MW}$ at a power factor of 0.9 and is shown in Fig. 11 with the parameters given in Table IV. For simplicity the loads are taken to have constant power.

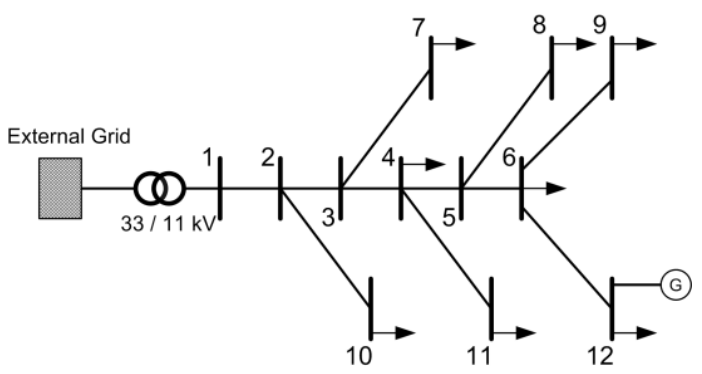

Fig. 11. Simulation model of $11 \mathrm{kV}$ residential feeder

The simulation is performed with multiple small generators connected in parallel at bus 12 , to give a total capacity of 2 MW, with characteristics as defined previously for the 31.5 $\mathrm{kVA}$ alternator in Table I. The point of re-closure to the main system is the line connecting buses 6 and 12. As the most severe voltage deviations will occur close to the generator, the voltage transient at bus 12 is shown for synchronizations of 50 degrees in Fig. 12 and Fig. 13. As expected from the results in 
Section II, the maximum voltage deviation occurs when the rotor lags the mains. This has recovered to within $6 \%$ of nominal by $50 \mathrm{~ms}$ after the event. The rotor leading mains synchronization has a voltage rise recovering in a similar time period.

TABLE IV

$11 \mathrm{kV}$ FEEDER DATA

\begin{tabular}{|c|c|c|c|c|}
\hline $\begin{array}{l}\text { From } \\
\text { (bus) }\end{array}$ & $\begin{array}{l}\text { To } \\
\text { (bus) }\end{array}$ & (ohms) & (ohms) & $\begin{array}{l}\text { Load } \\
(\mathrm{MW})\end{array}$ \\
\hline 1 & 2 & 0.077 & 0.078 & 0 \\
\hline 2 & 3 & 0.232 & 0.235 & 0 \\
\hline 2 & 10 & 1.868 & 0.700 & 0.27 \\
\hline 3 & 4 & 0.522 & 0.528 & 0.15 \\
\hline 3 & 7 & 2.088 & 0.783 & 0.27 \\
\hline 4 & 5 & 0.232 & 0.235 & 0 \\
\hline 4 & 11 & 1.868 & 0.700 & 0.27 \\
\hline 5 & 8 & 1.978 & 0.742 & 0.27 \\
\hline 5 & 6 & 0.522 & 0.528 & 0.15 \\
\hline 6 & 9 & 1.649 & 0.587 & 0.27 \\
\hline 6 & 12 & 1.868 & 0.700 & 0.27 \\
\hline
\end{tabular}

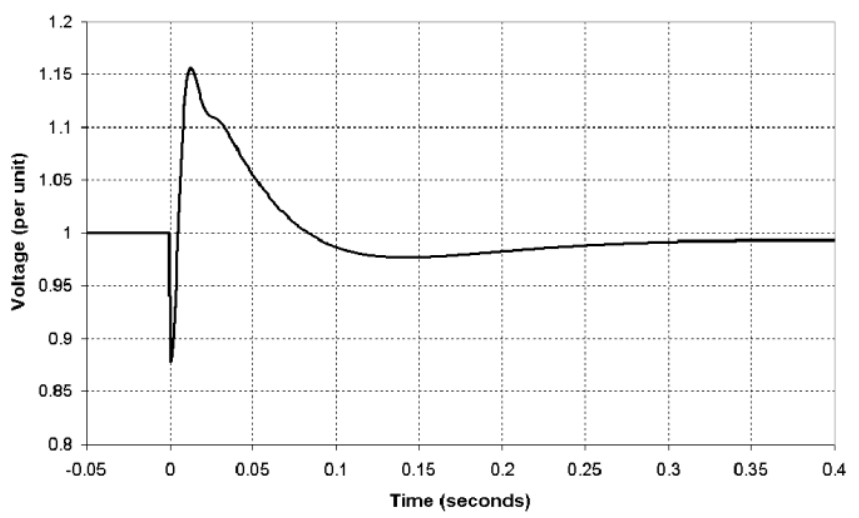

Fig. 12. Simulation to show voltage variation at bus 12 during out-of-phase synchronization where islanded system leads mains by 50 degrees

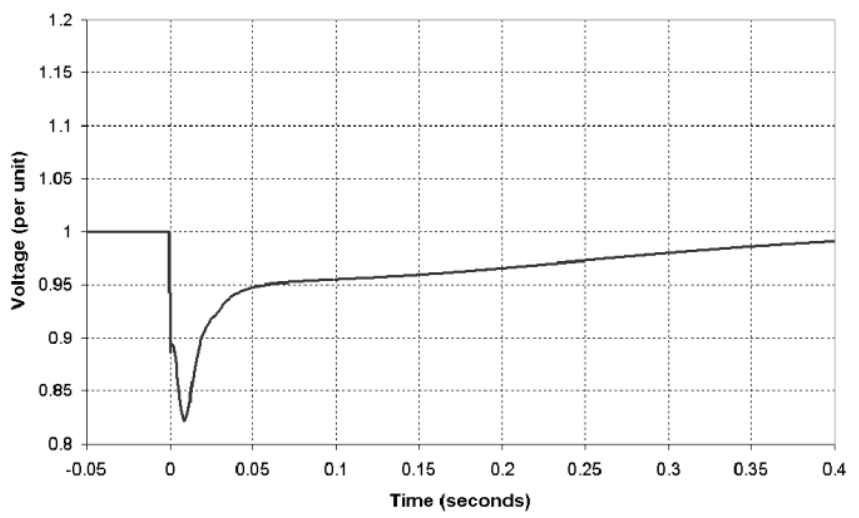

Fig. 13. Simulation to show voltage variation at bus 12 during out-of-phase synchronization where islanded system lags mains by 50 degrees

Fig. 14 gives the peak voltage drop and rise for different synchronization angles. The results show that out-of-phase synchronization would indeed cause appreciable voltage dips on the system, especially at larger angles. In keeping with the proposition from Section II that a 50 degrees synchronization is acceptable, then the system would expect to receive a voltage deviation of about $20 \%$.

A 50 degrees synchronization produces a voltage deviation less than that in [9] that will cause contactors to drop out. However the voltage deviation will affect electronic devices without sufficient energy storage. Despite this, low angle synchronizations have less severe system voltage effects than 3-phase short-circuits and the voltage transient is no more severe than that described in [11].

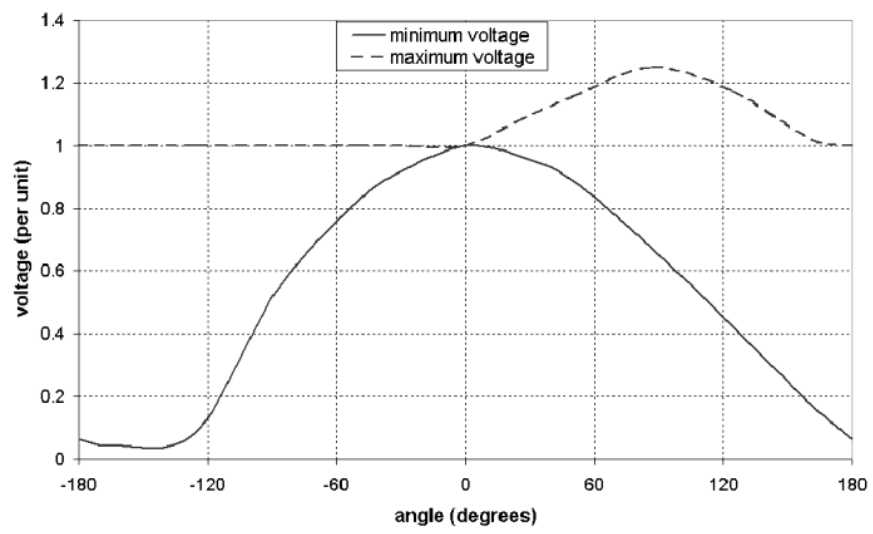

Fig. 14. Peak voltage deviation for different out-of-phase synchronization angles of islanded system

\section{CONCLUSION}

The effect that out-of-phase synchronization has on a small $31.5 \mathrm{kVA}$ alternator was investigated through experiment. Measurements were taken of voltage, current, frequency and transient rotor angle, with torque being inferred from rate of change of frequency. Peak torques and currents for synchronizations at 50 degrees were found to be less than that of a three-phase short circuit. It has been proposed that a synchronization angle of 50 degrees would be acceptable for small generators. The results also show that there is a difference between leading and lagging synchronizations that can be described by machine theory. If the rotor leads the mains before synchronization there is higher shaft torque, but if the rotor lags the mains there are higher winding currents.

A simulation was performed to give the expected voltage deviations that would occur when out-of-phase re-closure takes place between islanded and main power systems. This is most severe close to the terminals of the dispersed generator. For 50 degrees synchronizations, the voltage deviation is highest when the island lags the mains, this being a dip in voltage. In an island leading mains re-closure there is a voltage rise.

The implications of this work are that synchronization windows for small alternators could be increased significantly beyond that which would be regarded conventionally as being acceptable for large power system generators. The difference between leading and lagging synchronizations is also interesting as it suggests that the window could be skewed to one side depending on the desired torque, current and voltage deviation limits. 
For the proposed synchronous islanded operation to be applied to a large scale system other issues must be addressed. The communication delay in transmitting the reference signal and its affect on the control system are of primary concern. The manner in which the voltage phase angle varies throughout the power system also needs to be assessed. These two aspects are currently under investigation by the authors.

In addition it is important in any islanding scheme that proper procedures are adopted to ensure personnel safety, prevention of unearthed operation and acceptable power quality.

\section{REFERENCES}

[1] X. Ding, P. A. Crossley, D. J. Morrow, "Future distribution networks with distributed generators capable of operating in islanded mode," Universities Power Engineering Conference, UPEC 2004, 39 $9^{\text {th }}$ International, 6-8 September 2004, pp 773 - 776, vol. 1

[2] R. Best, D. J. Morrow, P. Crossley, "Phase difference control of a dcmotor driven alternator," Universities Power Engineering Conference, UPEC 2005, 40 ${ }^{\text {th }}$ International, 7-9 September 2005, pp 176-180, vol. 1

[3] C. J. Cudworth, J. R. Smith, "Steam turbine generator shaft torque transients: a comparison of simulated and test results," IEE Proceedings, vol. 137, pt. C, no. 5, September 1990

[4] D. Stojanovic, D. Petrovic, N. Mitrovic, "Torsional torques of big turbine-generator shafts due to malsynchronization," $10^{\text {th }}$ Mediterranean Electrotechnical Conference, MEleCon 2000, vol. 3, pp 1051 - 1054

[5] A. J. Wood, "Synchronizing out of phase," Transactions of AIEE, Part III - power apparatus and systems, vol. 76, pp 1- 10, April 1957

[6] M. Canay, "Stresses in turbogenerator sets due to electrical disturbances", Brown Boveri Review, vol. 62, no. 9, pp 435 - 443, September 1975

[7] D. B. Mehta, B. Adkins, "Transient torque and load angle of a synchronous generator following several types of system disturbance," IEE Proceedings, Part A - Power Engineering, vol. 107, no. 31, pp 61 74, February 1960

[8] H. S. Kirschbaum, "Transient electrical torques of turbine generators during short circuits and synchronizing," Transactions of AIEE, vol. 64, pp $65-70$, February 1945

[9] ANSI/IEEE Std 242-1986, IEEE Recommended practice for protection and co-ordination of industrial and commercial power systems, pp 390 397,1986

[10] S. Persaud, B. Fox, D. Flynn, "Impact of remotely connected wind turbines on steady state operation of radial distribution networks," Generation, Transmission and Distribution, IEE proceedings, vol. 147, vo. 3, pp 157 - 163, May 2000

[11] BS EN 50160:2000, "Voltage Characteristics of electricity supplied by public distribution systems," pp $14-15,2000$

\section{BIOGRAPHIES}

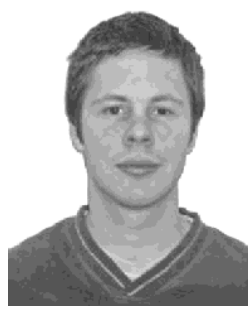

Robert J. Best was born in Belfast, Northern Ireland in 1980. He received the M.Eng degree from the Queen's University Belfast, Belfast, UK, in 2004.

Since graduating he has been with the Power and Energy Research Centre at Queen's University Belfast, Belfast, UK. His placements as an undergraduate were with Northern Ireland Electricity and Helsinki Energy. He is currently working towards the $\mathrm{Ph} . \mathrm{D}$ degree in power system islanding.

Mr. Best is a member if the Institution of Engineering and Technology.

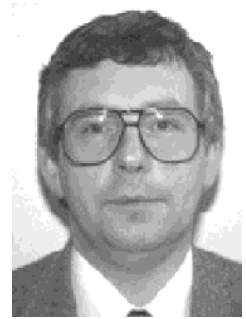

D. John Morrow (M'99) was born in Dungannon, Northern Ireland, in 1959. He received the B.Sc and Ph.D. degrees from Queen's University Belfast, Belfast, U.K., in 1982 and 1987, respectively.

Since 1987, he has been a Lecturer in electric engineering at Queen's University Belfast, Belfast, UK with research and consulting interests in electric power systems, power system instrumentation, and gen-set controllers.

Dr. Morrow is a member of the Institute of Engineering and Technology and also a member of the IEEE PES Excitation Systems Subcommittee working group since 1999.

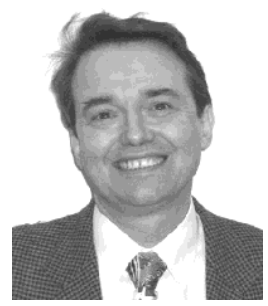

Peter A. Crossley (M'95) was born in the U.K. in 1956. He received the B.Sc. degree from the University of Manchester, Manchester, U.K., formerly UMIST, in 1977 and the Ph.D. degree from the University of Cambridge, Cambridge, U.K., in 1983.

$\mathrm{He}$ is a Professor of electrical engineering at the University of Manchester, Manchester, U.K. He has been involved in the design and application of protection systems for many years, with GEC, ALSTOM, Queen's University Belfast and The University of Manchester. He has published numerous technical papers on power system protection, embedded generation, and condition monitoring.

Professor Crossley is an active member of various CIGRE, IEEE, and Institution of Engineering and Technology committees on protection and control. 